\title{
Optimal Operation of Smart Grids Including Distributed Generation Units and Plug in Vehicles
}

\author{
A. Bracale ${ }^{1}$, P. Caramia ${ }^{1}$ and D. Proto ${ }^{2}$ \\ ${ }^{1}$ Department for Technologies, \\ University Parthenope of Napoli, Italy \\ Centro Direzionale di Napoli, Is. C4 - 80143 Napoli (Italy) \\ Fax number: +39 081 5476777, e-mail: antonio.bracale@uniparthenope.it, pierluigi.caramia@uniparthenope.it \\ ${ }^{2}$ Department of Electrical Engineering \\ University Federico II of Naples \\ Via Claudio, 21 I - 80125 Napoli (Italy) \\ Fax number: +39081 2396897, e-mail: danproto@unina.it
}

\begin{abstract}
The paper deals with the optimal operation of a Smart Grid (SG) including distributed resources based on dispersed generation (DG) units and plug-in vehicle fleets with the aim of furnishing some services both inside the SG and outside to the interconnected electrical system. The distributed resources are connected through power electronic interfaces and are coordinated by a centralized control system to provide the usual energy service as well as some ancillary services such as reactive power control and compensation for some continuous Power Quality (PQ) disturbances into the SG. In addition, plugin vehicle fleets are coordinated to charge/discharge their storage systems with the aim to perform the Smart Charging service, so as to provide regulation service for the interconnected electrical system, as well as to compensate the variability of DG units powers based on uncertain primary sources. Computer time domain simulations were effected on a low voltage 30-bus SG including wind turbine, photovoltaic systems and plug-in vehicles.
\end{abstract}

\section{Key words}

Smart Grid, Energy Storage System, Renewable Energies, Plug-in vehicles.

\section{Introduction}

The level of penetration of plug-in (electric or hybrid) vehicles is significantly growing and it is supposed to increase still more in the near future due to their potential to reduce emission levels as well as costs of transportation. Their inclusion in smart grids and the integration with renewable distributed generators lead to a series of challenges in grid operation, especially in terms of several services that can improve the operation of distribution networks.

Plug-in vehicles, in fact, can have the multiple roles of loads and energy sources since they are intrinsically distributed energy storage systems. Most vehicles are typically driven only a few hours per day and are parked the rest of the time (during the night or work). This characteristic gives the opportunity to furnish several services to the grid while optimizing the charging and discharging operations [1]. It has to be noted that, rather than with individual vehicle batteries, effective impact on grid service provision can be obtained by grouping together a large number of vehicles through an aggregator.

A certain number of aggregated parked plug-in vehicles, could, theoretically, provide several important services to the grid such as regulation, peak power, spinning reserve and other ancillary services $[1-3]^{1}$. In practice, only some of them are an attractive market opportunity for plug-in vehicles.

The types of services that can be furnished to the grid can require both two-way or one-way energy flows to the distribution network.

In literature, the services that can be supplied from the plug-in vehicles requiring a two-way energy flow from and to the network are usually referred to as Vehicle-togrid (V2G) [2].

On the other hand, a particular service that requires a one-way energy flow from the distribution network to the vehicle, is referred to as Smart Charging [1]. This last service can be considered a part of the abovementioned regulation service. In fact, in general an aggregation of controllable loads can be used to mach, at all times during the operation of the grid, the power generated and the power consumed by loads (Demand Dispatch); plugin vehicles, when parked, can be considered an aggregation of controllable loads.

In addition, when included in a SG, the plug-in vehicle fleet, connected to the grid through a bidirectional battery charger [4-6], can also be integrated with other energy resources and all can provide in an optimal way some or all of the above services to the distribution grid to whom the $\mathrm{SG}$ is linked.

In this paper, the optimal operation of a SG including distributed resources based on renewable sources and plug-in vehicle fleets with the aim of furnishing some energy and ancillary services has been considered. DG

\footnotetext{
${ }^{1}$ Regulation service is based on the use of controllable generation units or aggregated loads to regulate frequency and voltage by matching generation to load demand; the ability to increase power generation (or decrease loads) from a baseline level is refferred to as 'regulation up' and the other to decrease power generation (or increase loads) from a baseline is referred to as 'regulation down'. Peak power is the use of generation units during peak load periods. Spinning reserve is an additional power capacity that can be requested in case of outage [1-3].
} 
units as well as the plug-in fleets are connected to the grid through power electronic converters.

The distributed resources are coordinated by a centralized control system (CCS) to provide the usual energy service as well as some system ancillary services, such as reactive power control and compensation for some continuous PQ disturbances (waveform distortions and slow voltage variations) [7]. In addition, plug-in vehicle fleets are coordinated to perform the Smart Charging service, so as to provide regulation service for the interconnected electrical system as well as to compensate, into the SG, the variability of DG units powers based on uncertain primary sources.

The paper is structured as follows. The technological issues related to the service provision are discussed in Section 2. In Section 3 the SG taken into consideration is described and the control techniques adopted are recalled. Section 4 shows some results of the time domain simulation of an actual SG that includes photovoltaic and wind turbine units together with plug-in vehicles coordinated by a CCS.

\section{Services furnished by Plug-in Vehicles and required technologies}

Analyses on services that can be provided from plug-in vehicles and their market opportunities are reported in $[1,2]$. By the above analyses it appears that the services for which plug-in vehicles are more suitable are those characterized by high power value and fast response. As mentioned before, a certain number of aggregated parked plug-in vehicles could, theoretically, provide several services to the grid such as regulation, peak power, spinning reserve and other ancillary services, but in practice, only some of them are nowadays attractive market opportunity; in practice, plug-in vehicles cannot provide base load power at a competitive price whereas peak power, spinning reserve and regulation are services that can be provided because of the short duration of supply.

Regarding peak power, the required duration of the generation units could be 3-5 h, which can present some difficulties for the vehicles because of the on board storage limitations. This could be overcome by drawing power sequentially by a series of vehicles (e.g.: in car parking). Anyway, since this service is needed for just a few hours per year, the potential revenue for this service is limited, so resulting an interesting market opportunity only under some circumstances [8,9].

More promising markets are spinning reserve and regulation. Spinning reserve is an attractive market opportunity for $\mathrm{V} 2 \mathrm{G}$ since it is paid for the amount of time the generators are available and ready (capacity price) even if no energy is produced; an extra amount is paid for the energy that is actually furnished if needed (energy price) [10]. Then, plug-in vehicles are paid for the time of the day they are plugged in even if the generating periods are quite short.

Compared to spinning reserve, regulation requires availability several times per day, a faster response (within a minute) and short duration of generation. Plugin vehicle may be very well suited for this market, because they can respond very quickly and, since they can perform both regulation up and down, there is only a little net discharge of batteries. An interesting case of regulation service is made through the so called "Smart Charging" service where aggregated plug-in vehicles are considered as an aggregation of controllable loads. Through the Smart Charging, plug-in vehicles can contribute to the grid operation in an effective way thanks to their potential for rapid response as well as their expected rapid growth in the near future. Rather than just charging at off-peak times, smart charging involves the control of the charging of each vehicle to meet both the needs of the vehicle owner (i.e. to have the vehicle charged at a certain time) and the needs of the grid (e.g.: matching generation and load, providing regulation, and avoiding overload in distribution networks due to the presence of many vehicles being charged at the same time).

For the provision of the above mentioned services to the grid, plug-in vehicles require three main elements [11]:

1) power connection for electrical energy flow;

2) control or logical connection, needed to signal to the vehicles when power is requested; and

3) on board precision metering.

Regarding the first point, an already commercially available configuration for supplying battery energy to the grid consists of an integrated motor controller/inverter that uses the same power electronics switching stage for motor control, battery charging and utility connection [11]. Other promising configurations can include the inverter stage in a common plug-in charger located at the vehicle parking; proposals for this configuration are reported in [8-10].

Regarding the management of the vehicles, the grid operator should communicate with an aggregate capacity of vehicles through an aggregator which would contract with the grid operator through day ahead and hour-ahead markets to provide the required services. In this way, through the aggregator, all the vehicles present in the smart grid would appear to the grid to be a large source of rapidly-controllable generation or load. Thus plug-in vehicle if equipped with Internet-enabled communications through Wi-Fi, power line carrier, etc. can be aggregated to provide a dispatchable load resource. The aggregator would determine how and when the vehicle would be charged using data communication. Finally, measurement of energy and power flow on the vehicle will require a meter. Data from the on board metering are sent to the aggregator for calculating the vehicle's contribution to the grid services.

Another technical issue which is critical for an effective provision of services to the grid is related to the choice of the vehicle battery. The most feasible technology is the lithium-ion (Li-Ion) for the high value of energy and power density compared to other technologies (e.g.: nickel metal hydride Ni-MH batteries commonly used in last hybrid vehicle generations), though the attributes of one battery cannot be generalized and the various technologies are in continuous development [12]. 


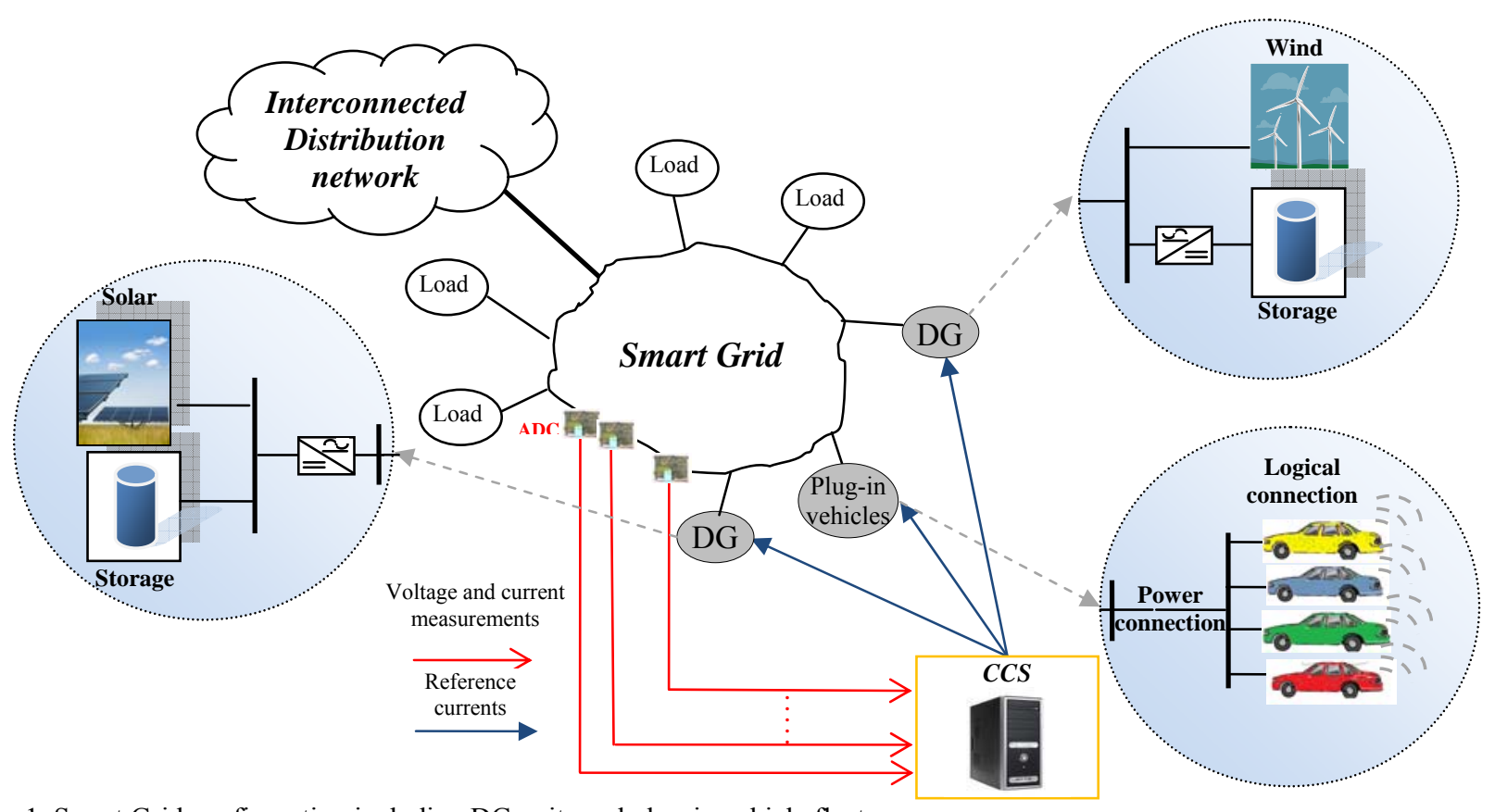

Fig. 1. Smart Grid configuration including DG units and plug-in vehicle fleet.

\section{The Smart Grid object of the analysis}

The Smart Grid considered for the analysis is a LV distribution system in which dispersed generators and plug-in vehicle fleets are connected.

A qualitative example of SG configuration is shown in Fig. 1, where the considered DG units, plug-in vehicles, interconnected distribution network and the centralized control system (CCS) are shown.

Dispersed generators and plug-in vehicle fleets are connected to the network by power converters whose adequate control permits the participation of these distributed resources in providing ancillary service [7].

The DG units are wind and photovoltaic cell-based generation units that, in the most general case, can include also a dedicated storage system composed of supercapacitors (SCs) and lead-acid batteries.

Overall, the distributed resources can be described as follows.

1) Photovoltaic-based (PV) systems generate DC energy. A storage system is present that is connected to the DC bus and includes a lead acid battery and an SC bank. Finally, a DC/AC converter is the interface to the $\mathrm{AC}$ bus where a privileged load and the grid are present. The connection to the smart grid is realized by means of a static-transfer switch.

2) Wind turbine (WT) systems are asynchronous machines directly connected to the smart grid. A battery storage system is connected to the same bus through a DC/AC converter.

3) The plug-in vehicle fleet is composed by a number of vehicles whose storage systems are lithium-ion batteries. The fleet is interconnected to the smart grid through a power converter.

The PV-based systems are normally connected to the network (grid connected mode) but they can be rapidly disconnected, thanks to the presence of the static switch, when a fault occurs (island mode). They are designed to provide: a) in normal operating conditions, energy to the grid and to the privileged load;

b) in critical operating conditions (e.g.: in presence of faults), energy only to the privileged load (back up service).

Furthermore, through an adequate control strategy of the interfacing converters, all the static converters of the DG units can perform voltage regulation and compensation of waveform distortions inside the Smart Grid [7]. In fact, a centralized control system (CCS) manages and coordinates the distributed resources in order to partial compensate or eliminate continuous PQ disturbances (e.g.: waveform distortions) and to obtain the proper allocation of reactive powers that can be produced by the units to improve the voltage profile at SG buses. The CCS furnishes to the DG units converters the reference currents for waveform distortions compensation inside the SG and the reference signal at which the unit has to operate for the improvement of the voltage profiles at all SG busbars or particular buses; the CCS operates as shown in [7, 13-17].

The plug-in vehicle fleet performs the "Smart Charging". In particular, a reference signal of active power for charging is sent to the plug-in vehicle fleets to contribute, in real time, to the demand dispatch service.

Besides the 'Smart Charging', the plug-in vehicle fleets can also be used as energy storages to be coordinated with the solar/wind farms included in the SG for providing the compensation of the variability of these uncertain sources. In this case, on the basis of the input information derived by the SG's loads requirements, wind/solar plants real time power measurements and active power fixed by the energy agreements with the interconnected grid, the CCS calculates the charging/discharging power reference signal to be sent to the vehicle fleets. In the most general case, this last is able to guarantee the contractual active power and matching of generation and loads into the SG (Fig. 2). 


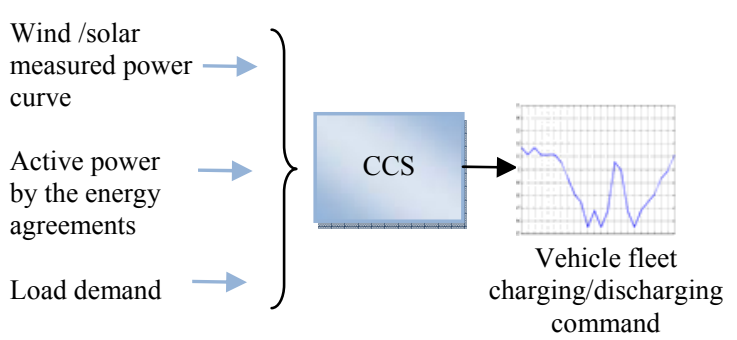

Fig. 2 Vehicle fleet charging/discharging command for compensation of uncertain DG units into the SG

\section{Numerical Applications}

The simulations were performed with reference to the 30busbar LV balanced 3-phase smart grid shown in Fig.3. The three-phase short circuit power at the $20 \mathrm{kV}$ bus is $\mathrm{P}_{\mathrm{sc}}=400 \mathrm{MVA}$; the $\mathrm{MV} / \mathrm{LV}$ transformer is rated at 250 $\mathrm{kVA}$ with $\mathrm{v}_{\mathrm{cc}, \%}=4.2 \%$.

The line parameters are reported in [17]. The loads, whose active powers are given in Table I, are three-phase loads, all operating at $\cos \varphi=0.9$. The non-linear loads are two three-phase, $\mathrm{AD} / \mathrm{DC}$ converters connected at busbars \#17 and \#27; they are characterized by firing angles of $\alpha=20^{\circ}$ and rated DC load powers of $2 \mathrm{~kW}$ and $14 \mathrm{~kW}$, respectively.

The SG includes a plug-in vehicle fleet, two PV and one WT DG units. The plug-in vehicle fleet, a $20 \mathrm{~kW}$ storage unit located at busbar \#2, is a Li-Ion battery unit connected to the network through a DC/AC converter.

The PV units of $10 \mathrm{~kW}$ peak power are located at busbars $\# 9$ and \#15, and are connected through DC/AC converters. The WT unit, characterized by a $7.5 \mathrm{~kW}$ asynchronous generator, is located at busbar \#24.

All DG units receive reference signals from the centralized control system in order to perform adequate ancillary services and, in particular, the voltage regulation and the partial compensation or elimination of voltage harmonic distortion inside the SG. The PV units also provide an energy service to a local privileged load. With reference to the plug-in vehicle fleet, the following two case studies were analyzed:

A. the plug-in vehicle fleet performs the Smart Charging service and participates to the SG voltage harmonic compensation;

B. the plug-in vehicle fleet performs the matching of generation and loads into the SG by integrating the uncertain energy sources and participates to the SG voltage harmonic compensation.

In the following, some results of time domain simulations of the $\mathrm{SG}$ in Fig. 3 modelled in Matlab $^{\circledR}$ SimPowerSystem and referred to the above case studies are reported.

\section{Case study A}

In this case study, the results of a $12 \mathrm{~s}$ time domain simulation were reported. Fig. 4 shows the active power of the plug-in vehicle fleet and the active power reference signal $\left(\mathrm{P}_{\text {ref }}\right.$ in Fig. 4) required for providing the Smart Charging service effected by the vehicle fleets.
Table I

\begin{tabular}{|c|c|}
\hline & Load active power \\
\hline $\mathrm{C}_{4}$ & 3 \\
\hline $\mathrm{C}_{5}$ & 3 \\
\hline $\mathrm{C}_{6}$ & 6 \\
\hline $\mathrm{C}_{7}$ & 3 \\
\hline $\mathrm{C}_{8}$ & 3 \\
\hline $\mathrm{C}_{13}$ & 3 \\
\hline $\mathrm{C}_{14}$ & 3 \\
\hline $\mathrm{C}_{18}$ & 3 \\
\hline $\mathrm{C}_{21}$ & 2.5 \\
\hline $\mathrm{C}_{26}$ & 3 \\
\hline $\mathrm{C}_{28}$ & 3 \\
\hline $\mathrm{C}_{30}$ & 6 \\
\hline
\end{tabular}

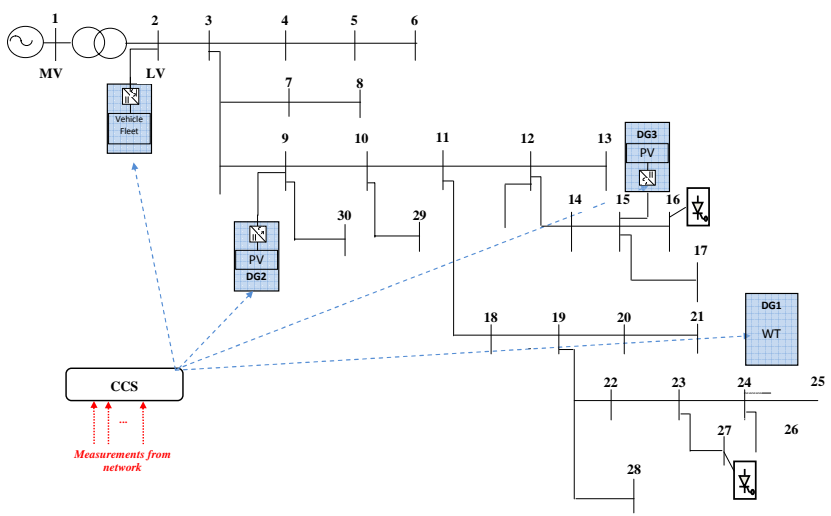

Fig. 3. LV Smart Grid with CCS

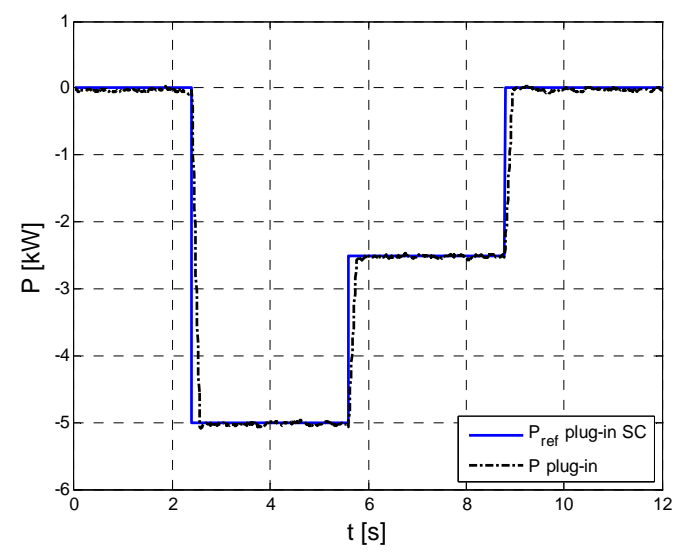

Fig. 4. Case Study 1: Active power of plug-in vehicle fleet and reference signal for demand dispatch

From the analysis of Fig. 4, it can be noted that the Smart Charging acts in an effective way.

Fig. 5 shows the voltage profiles of the SG busbars in the following cases: 1) without DG units (passive network), 2) with $D G$ units performing the centralized reactive power control. Fig. 5 refers to the steady state conditions in the time interval $[9,12] \mathrm{s}$. From the analysis of Fig. 5, it can be noted that the centralized reactive power control significantly improves the voltage profile of the network buses.

Fig. 6 shows the voltage Total Harmonic Distortion (THDv) at all SG busbars without DG units (passive network) and with DG units performing centralized voltage regulation and distributed resources (DG units and plug-in vehicle fleet) performing compensation of the 5 th, 7 th, 11 th, and 13 th voltage harmonics. 


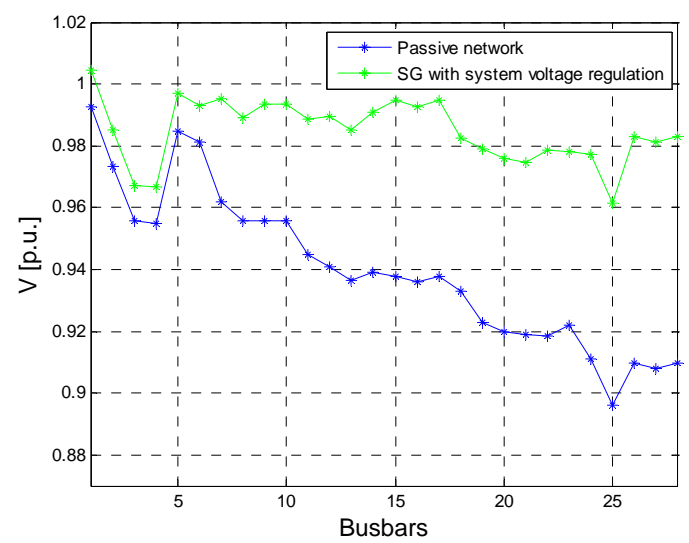

Fig. 5. Case Study 1: Smart Grid voltage profiles

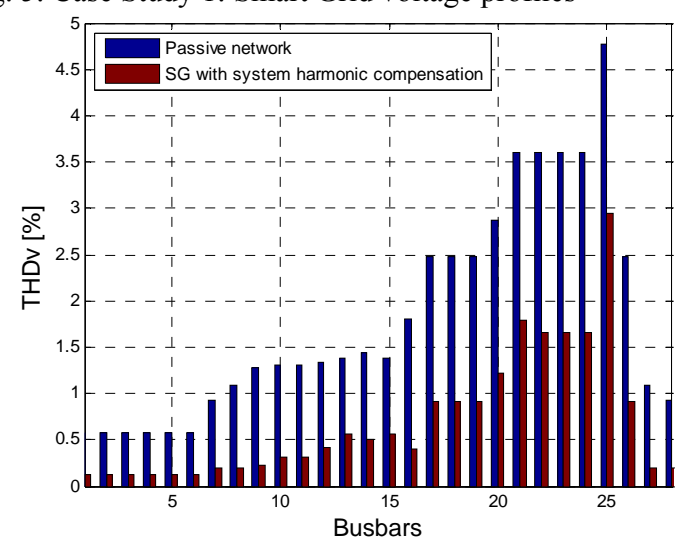

Fig. 6. Case Study 1: $\mathrm{THD}_{\mathrm{V}}$ at all system busbars

Fig. 6 shows the advantages that the distributed resources bring in terms of a significant reduction of THDv values at all the buses of the SG.

\section{Case study B}

The results of a $2 \mathrm{~h}$ time domain simulation were reported. In this case study, variations on both PV and wind DG units active powers (Fig. 7) were simulated. Figure 8 shows the total supplied active power $\left(\mathrm{P}_{\text {grid }}+\mathrm{P}_{\mathrm{DG}}\right)$ and the load power $\left(\mathrm{P}_{\text {loads }}\right)$ demand versus time. The plug-in vehicle fleet compensates for the variations of the power supplied by DG units in order to match generation and load into the SG keeping constant the power furnished by the interconnected grid $\left(\mathrm{P}_{\text {grid_ref }}=35 \mathrm{~kW}\right)$. The CCS active power reference signal $\left(\mathrm{P}_{\text {ref }}\right)$ sent to the vehicle fleets and the corresponding vehicle fleet active power $\left(\mathrm{P}_{\text {plug-in }}\right)$ are reported in Fig. 9. From the analysis of Figs. 7, 8 and 9 it can be noted that the vehicle fleet initially absorbs active power from SG (Fig. 9) since there is a significant DGs power production (Fig. 7) that, together with the contractual active power furnished by the interconnected grid, is greater than that required by the $\mathrm{SG}$ loads ( $\mathrm{P}_{\text {loads }}$ in Fig. 8 ).

After 48 minutes, wind and PV units active powers (Fig. 7) are reduced due to the variations of wind and solar primary sources; then, WT and PV units active powers are not sufficent to supply loads while guaranteeing $P_{\text {grid ref }}=35 \mathrm{~kW}$ (Fig. 8). Thus, the vehicle fleet furnishes the remaining needed active power (Fig. 9).

Fig. 10 shows the voltage profiles of the SG busbars in the following cases: 1) without DG units (passive network) and 2) with DG units performing the centralized reactive power control.

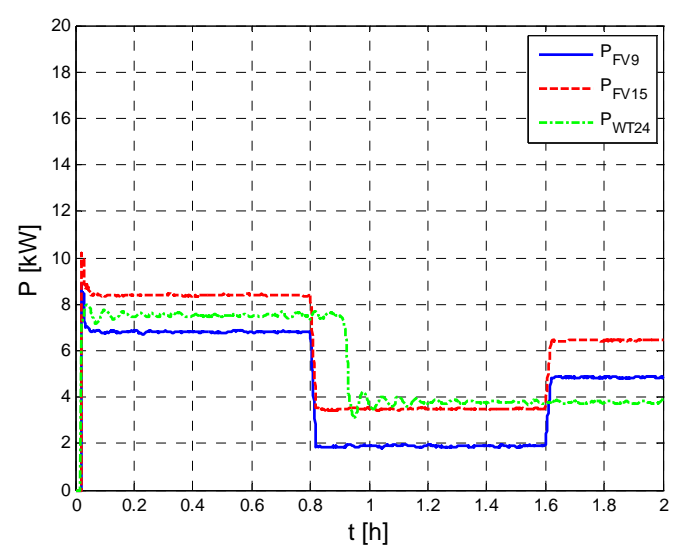

Fig. 7. Case Study 2: Active power of wind DG unit at busbar \#24 and PV DG units at busbars \#9 and \#15 versus time

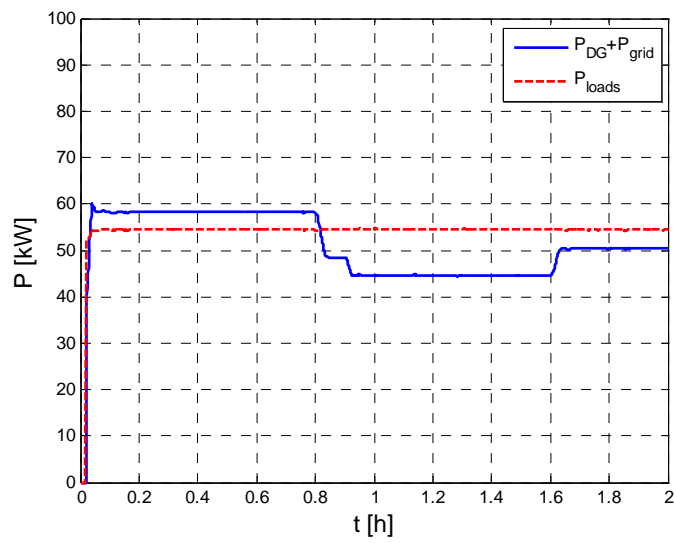

Fig. 8. Case Study 2: Total supplied active power $\left(\mathrm{P}_{\text {grid }}+\mathrm{P}_{\mathrm{DG}}\right)$ and load power demand $\left(\mathrm{P}_{\text {loads }}\right)$ versus time

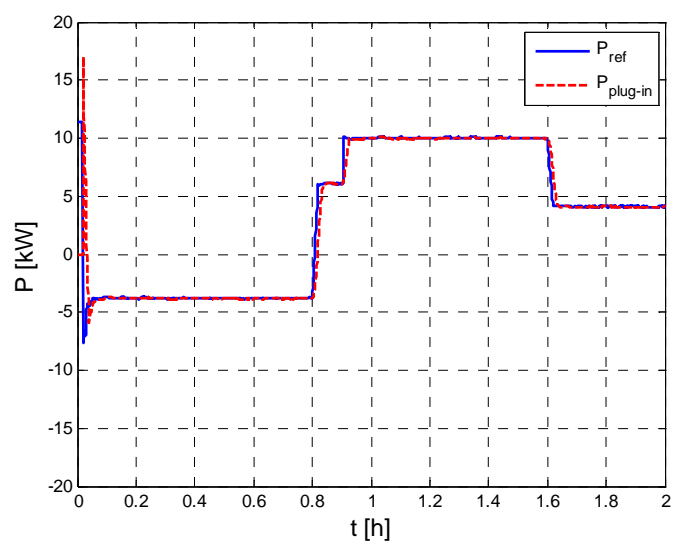

Fig. 9. Case Study 2: Active power of plug-in vehicle fleet and reference signal for uncertain DG units compensation

Fig. 10 refers to the steady state conditions in the last minutes of the second hour. From the analysis of Fig. 10, it can be noted that the centralized reactive power control, once again, improves the voltage profile of the network buses. As in case study 1, similar reduction of THDv values in all the buses of the SG are obtained (Fig. 11).

\section{Conclusions}

The problem of optimal operation of a Smart Grid including distributed resources such as wind and photovoltaic cell-based generation units and plug-in vehicle fleets has been analysed. 


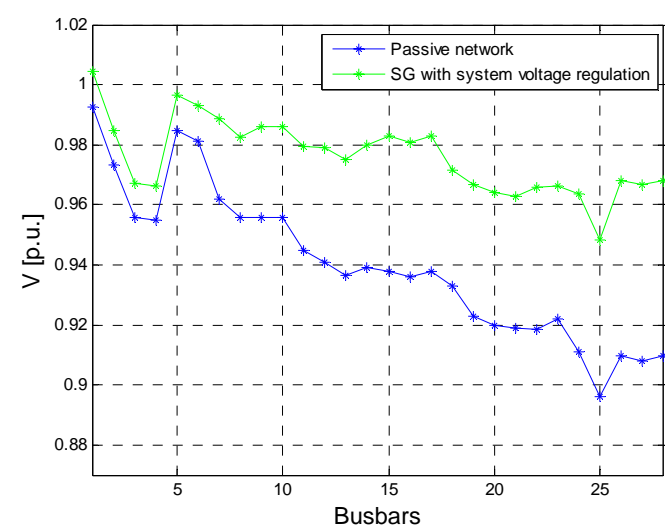

Fig. 10. Case Study 2: Smart Grid voltage profiles

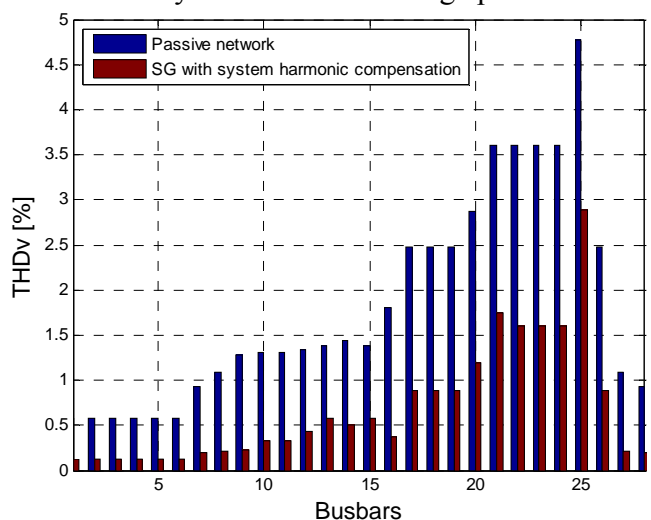

Fig. 11. Case Study 2: $\mathrm{THD}_{\mathrm{V}}$ at all system busbars

A CCS manages and coordinates the distributed resources in order to furnish ancillary services external and internal to the SG. In particular, the presence of a plug-in vehicle fleet enables to perform both the smart charging service to the interconnected grid and the compensation of variability of DG units powers based on uncertain primary sources into the SG. In addition, the CCS coordinates the DG units to provide some ancillary services such as reactive power control and compensation for some continuous PQ disturbances into the SG.

Time domain simulations on a 30-bus low voltage SG with DG units based on uncertain primary sources gives evidence of the effectiveness of the considered control strategies and the feasibility of the results for services both external and internal to the SG.

\section{Acknowledgement}

The authors would like to thank Professor G. Carpinelli for his support, advice and helpful comments.

This paper is funded in the framework of the agreement of the MSE - CNR Program for Triennial Plan of the System Research and Annual Operational Plan for Research and Development Activities of general interest for the National Electrical System.

\section{References}

[1] A. Brooks, E. Lu, D. Reicher, C. Spirakis, B. Weihl: "Demand Dispatch: Using Real-Time Control of Demand to Help Balance Generation and Load", IEEE Power \&Energy Magazine, May-June 2010, pp.20-29.

[2] W. Kempton, J. Tomic: "Vehicle-to-grid power fundamentals: Calculating capacity and net revenue",
Journal of Power Sources, Volume 144, Issue 1, June 2005, pp. 268-279

[3] J.B. Campbell, T.J. King, B. Ozpineci, D.T. Rizy, L.M Tolbert, Y. Xu, X. Yu: "Ancillary Services Provided from DER”, OAK Ridge National Laboratory, Report ORNL/TM-2005/263, December 2005

[4] X. Zhou; G. S.Wang; Lukic, S.Bhattacharya, A.Huang: "Multi-function bi-directional battery charger for plug-in hybrid electric vehicle application," Energy Conversion Congress and Exposition, 2009. ECCE 2009. IEEE, vol., no., pp.3930-3936, 20-24 Sept. 2009

[5] X. Zhou, S. Lukic, S. Bhattacharya, A. Huang: "Design and control of grid-connected converter in bi-directional battery charger for Plug-in hybrid electric vehicle application," Vehicle Power and Propulsion Conference, 2009. VPPC '09. IEEE, pp.1716-1721, 7-10 Sept. 2009.

[6] Yu Du; X. Zhou; S. Bai; Lukic, S.; Huang, A.; , "Review of non-isolated bi-directional DC-DC converters for plugin hybrid electric vehicle charge station application at municipal parking decks", $25^{\text {th }}$ IEEE APEC Conference 2010, pp.1145-1151, 21-25 Feb. 2010.

[7] R. Angelino, A. Bracale, G. Carpinelli, M. Mangoni, D. Proto: "Dispersed Generation Units Providing System Ancillary Services in Distribution Networks by a Centralized Control", accepted for publication to IET Renewable Energy.

[8] W. Kempton, S. Letendre, Electric vehicles as a new power source for electric utilities, Trans. Res. D 2 (3) (1997) $157-175$

[9] W. Kempton, J. Tomic, S. Letendre, A. Brooks, T. Lipman, Vehicle-to-Grid Power: Battery, Hybrid and Fuel Cell Vehicles as Resources for Distributed Electric Power in California. Davis, CA: Institute of Transportation Studies Report June, 2001, http://www.udel.edu/V2G.

[10] J. Tomic, W. Kempton: "Using fleets of electric-drive vehicles for grid support", Journal of Power Sources 168 (2007) 459-468.

[11] B. Kramer, S. Chakraborty, B. Kroposki: "A review of plug-in vehicles and vehicle-to-grid capability", IEEE 34th Annual Conference of Industrial Electronics, IECON 2008, pp.2278-2283, 10-13 Nov. 2008

[12] J. Axsen, A. Burke, K. Kurani: "Batteries for Plug-in hybrid Electric Vehicles (PHEVs): Goals and the State of Technology circa 2008", Institute of Transportation Studies University of California Davis, CA, May 2008

[13] G. Carpinelli, A. Griffo, D. Lauria, A. Russo, "An optimalcontrol strategy for power quality enhancement in a competitive environment," Electrical Power and Energy Systems Vol. 29 (2007), pp. 514-525

[14] R. Caldon, R. Turri, V. Prandoni, S. Spelta: "Control Issues in MV Distribution Systems with Large-scale Integration of Distributed Generation." Bulk Power System Dynamics and Control - VI, August 22-27, 2004, Cortina d'Ampezzo, Italy.

[15] R. Angelino, A. Bracale, G. Carpinelli, D. Lauria, M. Mangoni, D. Proto: "Centralized Control of Dispersed Generators Providing Ancillary Services in Distribution Networks Part I: Theoretical Aspects," IEEE International Conference UPEC 2009, September 1-4, 2009, Glasgow

[16] R. Angelino, A. Bracale, G. Carpinelli, M. Mangoni, D. Proto: "Analysis of a Centralized Control System for Providing System Ancillary Services in Distribution Networks with Dispersed Generation Units", International Conference on Renewable Energies and Power Quality (ICREPQ'10), Granada (Spain), 23- 25 marzo, 2010.

[17] R. Angelino, A. Bracale, M. Mangoni, D. Proto: "Centralized Control of Dispersed Generators Providing Ancillary Services in Distribution Networks Part II: Numerical Applications," IEEE 44 ${ }^{\text {th }}$ UPEC 2009, September 1-4, 2009, Glasgow (GB). 